\title{
Costs of employee smoking in the workplace in Scotland
}

\author{
Steve Parrott, Christine Godfrey, Martin Raw
}

\begin{abstract}
Background-Employers have responded to new regulations on the effects of passive smoking by introducing a range of workplace policies. Few policies include provision of smoking cessation intervention.

Objective-To estimate the cost to employers of smoking in the workplace in Scotland to illustrate the potential gains from smoking cessation provision. Costs vary with type of smoking policy in place; therefore, to estimate these costs results from a survey were combined with evidence drawn from a literature review. Study design-A telephone survey of 200 Scottish workplaces, based on a stratified random sample of workplaces with 50 or more employees, was conducted in 1996. Additional evidence was compiled from a review of the literature of smoking related costs and specific smoking related effects. Results-167 completed responses were received, of which 156 employers (93\%) operated a smoking policy, 57 (34\%) operated smoke free buildings, and 89 (53\%) restricted smoking to a "smoke room". The research literature shows absenteeism to be higher among smokers when compared to non-smokers. The estimated cost of smoking related absence in Scotland is $£ 40$ million per annum. Total productivity losses are estimated at approximately $£ 450$ million per annum. In addition, the resource cost in terms of losses from fires caused by smoking materials is estimated at approximately $£ 4$ million per annum. In addition, there are costs from smoking related deaths and smoking related damage to premises. Conclusion-This study shows how smoking cessation interventions in the workplace can yield positive cost savings for employers, resulting in gains in productivity and workplace attendance which may outweigh the cost of any smoking cessation programme. (Tobacco Control 2000;9:187-192)
\end{abstract}

Keywords: costs of employee smoking; Scotland; smoking related absence

Smoking in the workplace has become an important issue in recent years. Awareness of the dangers of passive smoking has raised concerns about the health of employees and the need for protection from environmental tobacco smoke. ${ }^{1}$ Furthermore, as a result of European Union (EU) directives and recent legal cases (most notably the Veronica Bland settlement ${ }^{2}$ ), the responsibility for protecting employees from such dangers clearly lies with the employer, making it necessary for firms to pay close attention to the problem.

In addition, employee smoking imposes considerable costs on employers. Evidence shows that workers who smoke are absent from work more often than their non-smoking colleagues, ${ }^{34}$ which results in a loss of output. Time is also lost as workers take "smoke breaks" or, if permitted, smoke "on the job". Insurance premiums may be higher as a result of claims for fire damage caused by smokers' materials if premiums are based on experience rated previous claims. In addition, tobacco smoke may also result in damage to plant and machinery. ${ }^{5}{ }^{6}$

There is a limited literature on the costs of workplace smoking. Kaiserman estimated workers' absenteeism to cost approximately US $\$ 80$ billion (at 1991 prices) by examining earnings data. ${ }^{7}$ The author also estimated a loss of approximately $\$ 10.5$ billion from lost future income caused by premature death. Helyer's study of tobacco use in the US Department of Defense valued the cost of productivity losses as a result of smoking breaks and hospitalisation at $\$ 346$ million per annum (1995 prices). ${ }^{8}$ In Australia, Collins and Lapsley pointed to the significant costs to society and industry as a result of drug misuse. The estimated cost of tobacco use to employers was A \$3.386 million at 1992 prices, which comprised of absenteeism and reduced productivity. ${ }^{9}$ The costs of employee smoking at Telecom Australia was investigated by Hocking and colleagues using aetiological fractions to attribute proportions of illness to smoking. Basing costs on each worker's daily salary, the total cost to the employer as a result of smoking related absence was $\$ 16.5$ million per annum. ${ }^{10}$ Nelson estimated the cost of employee smoking at $£ 100$ million per annum (1984 prices) in terms of productivity losses, absenteeism and fire damage. ${ }^{5}$ However, the methodologies used to conduct the cost estimates in these studies varies significantly, and the majority of the literature to date has concentrated on the USA.

The response by most employers in Scotland to changes in regulations has been to introduce some form of smoking policy. Few employers have, however, considered the costs they bear due to employees smoking and the potential benefits of providing smoking cessation interventions. The purpose of this research was to provide an estimate of the costs imposed on 
Table 1 Employment in Scotland 1994

\begin{tabular}{llcr}
\hline SIC code & Group & Employment & $\%$ \\
\hline 0 & Agriculture, forestry, and fishing & 25000 & 1.3 \\
1 & Energy and water supply & 50000 & 2.6 \\
2 & Metal manufacturing and chemicals & 36000 & 1.8 \\
3 & Metal goods, engineering, and vehicles & 148000 & 7.6 \\
4 & Other manufacturing & 166000 & 8.5 \\
5 & Construction & 102000 & 5.2 \\
6 & Wholesale distribution, hotels and catering & 406000 & 20.8 \\
7 & Transport and communication & 109000 & 5.6 \\
8 & Banking, insurance, and finance & 202000 & 10.4 \\
9 & Education, health services, and other & 704000 & 36.1 \\
& Total & 1948000 & \\
\hline
\end{tabular}

Source: Employment Gazette policies currently in place and the attitudes of employers to such policies. A stratified random sample was based on the number of workers in Scotland employed in the different standard industrial classification (SIC) categories. Employment in the 10 SIC sectors in Scotland is shown in table 1

A list of Scottish companies was compiled from local authority business directories, the Kompass ${ }^{12}$ directory of businesses, and lists of local authorities and health boards. This followed the method of Godfrey and colleagues. ${ }^{13}$ The study did not exclusively use Kompass as a source of company information as has been done in several previous surveys since this directory is limited to industrial suppliers and excludes firms in the consumer good industries and also most public sector organisations.

The survey was based on employers with over 50 employees, in order to estimate the proportions covered by different regulations. The results were then applied to the total Scottish workforce to estimate the costs of employee smoking.

The number of firms in each sector were drawn from the SIC categories according to the proportion of the Scottish workforce employed in that sector. However, because of the distribution of Scottish employment across the 10 SIC sectors, some of the sectors were too small to provide meaningful results when presented in SIC codes. In order to present the findings by broad industrial groups, the results are presented by combining SIC codes. The groups used for this study were manufacturing (energy and water supply, manufacturing, engineering, and vehicles), non-office based services (construction, distribution, hotels and catering, transport, and communication) and office and public sector (banking, insurance, finance, education, health services, and other services).

Interviews were conducted with the individual responsible for smoking policies (usually personnel officers or health and safety officers) over the telephone and were based on a questionnaire. The full results are available from the authors by request.

\section{Results of the survey}

The survey generated 167 responses. In 33 of the companies approached it was not possible to speak to the person responsible for the policy after three attempts $(n=26)$, or there was no individual responsible for policy $(n=7)$. Of these 167 employer, 156 employers (93\%) operated some form of restrictive smoking policy (table 2). Restrictive policies were in place in all of the office and public sector workplaces sampled.

Of the 156 firms in the sample, $57 \%$ restricted smoking to a "smoking room" which was the most common policy across all three industrial groups. A smoke free building policy was operated by $37 \%$ of employers with a smoking policy. This was a similar result to that of the Department of Health ${ }^{14}$ finding that $40 \%$ of the UK workforce was working in a totally smoke free environment. Three ing in the workplace in Scotland. The data were collected in January and February 1996 in order to investigate the various smoking 
Table 2 Smoking policies in worksites in Scotland

\begin{tabular}{|c|c|c|c|c|}
\hline & Manufacturing & $\begin{array}{l}\text { Non-office } \\
\text { services }\end{array}$ & $\begin{array}{l}\text { Office and } \\
\text { public sector }\end{array}$ & Full sample \\
\hline Interviews completed & 41 & 49 & 77 & 167 \\
\hline Firms with a smoking policy & $35(85 \%)$ & $44(90 \%)$ & $77(100 \%)$ & $156(93 \%)$ \\
\hline Written smoking policy & $32(91 \%)$ & $31(70 \%)$ & $70(91 \%)$ & $133(85 \%)$ \\
\hline \multicolumn{5}{|l|}{ Type of policy } \\
\hline Smoke free building & $9(26 \%)$ & $18(41 \%)$ & $30(39 \%)$ & $57(37 \%)$ \\
\hline $\begin{array}{l}\text { Smoking allowed in } \\
\text { "smoke room" only }\end{array}$ & $25(71 \%)$ & $21(48 \%)$ & $43(56 \%)$ & $89(57 \%)$ \\
\hline $\begin{array}{l}\text { Smoking allowed at } \\
\text { certain times only }\end{array}$ & 0 & 0 & $3(4 \%)$ & $3(2 \%)$ \\
\hline Other & $1(3 \%)$ & $5(9 \%)$ & $1(1 \%)$ & $7(4 \%)$ \\
\hline
\end{tabular}

employers placed restrictions upon the times at which employees are allowed to smoke. Seven employers stated that the decision over whether to allow smoking in an office was based upon individuals' preferences.

Employers operating food manufacturing plants or using chemicals indicated that smoking bans were a statutory requirement because of health and safety legislation.

Of the 156 with a smoking policy, $26 \%$ indicated having experienced problems with the policy. The major problem identified was the loss of productivity experienced while smokers took cigarette breaks, which was perceived to be unfair by non-smokers $(n=17)$. This was especially the case when smokers could take unlimited breaks during the day. Concern was expressed at the adverse public image created by smokers congregating at the entrance to the building when a smoke free building policy was in operation $(\mathrm{n}=4)$, fly smoking in toilets $(n=6)$, and senior staff ignoring bans $(n=3)$.

Forty nine (29\%) of the 167 firms surveyed offered cessation help to employees wishing to stop smoking. Help was offered by 14 manufacturing employers (34\%), eight nonoffice based services (16\%), and 27 office and public sector based employers (27\%). Cessation help had been offered by 21 employers temporarily while a no smoking policy was introduced, but they indicated that there had been a very disappointing uptake and the decision was taken not to provide help as an ongoing policy.

Health benefits were the most commonly cited benefit perceived from a restrictive smoking policy $(\mathrm{n}=130)$. Other benefits were safety $(n=40)$, hygiene benefits $(n=30)$, wider cost savings $(n=19)$, legal benefits $(n=9)$, benefits to staff morale ( $n=9)$, and reduced absenteeism $(\mathrm{n}=2)$.

Seventeen employers cited reduced productivity as a major cost of imposing worksite smoking restrictions as smokers leave their tasks to smoke in permitted areas. Nine employers believed there was a cost involved when introducing a restrictive smoking policy, because of the costs such as releasing work space to provide a smoke room, or providing equipment such as extractor fans required for such a facility.

The majority of employers were aware of the health benefits of introducing a restrictive smoking policy. However, there appears to be a lack of awareness surrounding wider cost saving benefits of policies aimed to help employees stop smoking. Cost savings to the firm were not thought important, or had not been considered, despite evidence in the literature pointing to the potential savings to businesses. Reducing absence from work was only identified as a benefit by two of the 167 employers interviewed. The survey also showed that employees no longer expect to be able to smoke freely at work.

\section{Cost of employee smoking in Scotland}

Evidence shows that workers who smoke are absent from work more often than their non-smoking colleagues which results in a loss of output. Time is also lost as workers take "smoke breaks" or, if permitted, smoke "on the job". Insurance premiums may be higher as a result of claims for fire damage caused by smokers' materials, and tobacco smoke may also result in damage to plant and machinery. The following sections present the estimates of these costs based on the survey results and specific literature searches to provide estimates of the effects of smoking.

ABSENCE CAUSED BY SMOKING RELATED DISEASE In order to estimate the cost of absenteeism as a result of smoking in Scotland it is necessary to calculate:

- the prevalence of smoking among employees in Scotland;

- the productivity of labour;

- excess absence from work among smokers.

The prevalence of smoking among the employed population of Scotland is estimated at $33.2 \%$ for males and $36.2 \%$ for females. ${ }^{15}$ This prevalence is applied to the employed population to provide an estimate the total number of Scottish employees who smoke.

The following estimates use the human capital approach to calculating lost productivity by assuming that the value of productivity lost is equal to the wage rate. Average wage rates are used to approximate the productivity of labour. In the UK in 1998 the gross average hourly wage rates (including employee National Insurance contributions) for all industries were $£ 10.20$ ( $£ 11.22$ including employers' National Insurance contributions), and $£ 8.23$ ( $£ 9.05$ ) for men and women, respectively. ${ }^{16}$ These wage rates are used as it was inappropriate to disaggregate the employment data into individual categories because the sample size was small for some of the industrial groups. In addition, the industrial groupings were constructed from smaller groups where average earnings were not available in a disaggregated form.

Estimates of the cost of excess absence from work among smokers were taken from large surveys of workplace absenteeism identified in the literature. Van Tuinen and Land ${ }^{3}$ examined the Missouri Department of Health and found an excess absence among smokers of one hour a month - an average of 5.3 hours a month sick leave among 97 smokers, compared to 4.3 hours among 309 non-smokers. The study therefore estimates absence to be $23.2 \%$ higher among smokers. This result is lower than the estimates for male civil servants in the Whitehall study $(46 \%$ higher for short absences and $81 \%$ higher for long absences), 

Table 3 Employment and the estimated cost of absenteeism caused by smoking: Scotland
1997

\begin{tabular}{llll}
\hline & Male workers & Female workers & Total \\
\hline Employment & 902000 & 559000 & 1461000 \\
$\quad$ Full time & 109000 & 460000 & 569000 \\
$\quad$ Part time & 299464 & 202358 & 501882 \\
Estimated number of smokers & 36188 & 166520 & 202708 \\
$\quad$ Full time & $294926^{\star}$ & $252015^{\star}$ & $547041^{\star}$ \\
$\quad$ Part time & 2123468 & 1814507 & 3937975 \\
Smoking employees & $£ 11.22$ & $£ 9.05$ & \\
Excess sickness absence per annum (hours) & & & \\
Wage per hour (including NICs) & $£ 23825313$ & $£ 16426735$ & $£ 40252048$ \\
Cost of absenteeism & & \\
\hline
\end{tabular}

$\star$ Part time workers included as working 15.2 hours per week time worker. ${ }^{16}$ Source: Labour Market Trends, August 1999.

NICs, National Insurance contributions.

although it is similar to the estimates for female workers ( $9 \%$ and $37 \%$, respectively).

Tsai and colleagues examined a population of petrochemical workers using the Shell Oil Company's health surveillance system between 1986 and 1994. The study estimated an excess sickness absence of 3.2 days for women smokers and 2.6 days for male smokers. ${ }^{17}$

The estimates presented below are based on the results of the DuPont study. ${ }^{4}$ The results should be treated with caution, because of differences in institutional structure between the US and the UK, and the different penalties faced between countries as a consequence of absenteeism. However, the study was selected because of the large population $(n=45976)$ and diversified workforce. The results were presented as excess days absence per employee, which provides the information required to transform the estimates to other scenarios. The DuPont study estimates an excess absence from work among smokers of 0.90 days per year ( 7.2 hours per year), a result which is significant at a $99 \%$ confidence level. The estimated excess absence (which translates to $32.2 \%$ among smokers) is of a similar magnitude to the Missouri ${ }^{3}$ and the DuPont ${ }^{4}$ studies.

Using the estimates of the Dupont study ${ }^{4}$ the total cost of employee smoking in terms of excess absenteeism is therefore estimated to be almost $£ 40$ million per annum (table 3 ). This may be interpreted as a lower estimate of the cost. However, the cost of absenteeism will depend upon a number of factors. Firstly, the estimated excess absence among smokers, which will in turn depend upon the study population, and factors such as the level of sickness benefits. If the estimates are drawn from other studies the estimated cost will be different. For example, if the excess absence estimates from Van Tuinen and Land ${ }^{3}$ are used, the cost to Scottish employers of absenteeism as a result of employee smoking would be $£ 67$ million, while using Tsai's estimate, the cost increases to almost $£ 130$ million per annum. This may be interpreted as a higher estimate. These estimates, however, should not be treated as upper or lower bounds, but instead as indicators of the sensitivity of cost to changing key parameters.

These estimates appear very conservative when compared to the estimates of Nelson ${ }^{5}$ who estimated the excess sickness absence to be 7.3 days per annum among smokers in
Northern Ireland using social security statistics. Nelson's estimates were derived by applying smoking attributable proportions to the total days absent from work as a result of ischaemic heart disease, bronchitis, emphysema, and other respiratory diseases.

There are several key variables which will affect the magnitude of absenteeism cost estimates. The wage rate will be an important factor determining the cost of absenteeism. Estimated costs as a result of smoking by male employees exceed the costs of female employees partly as a result of the higher wages earned by men. The accuracy of this estimate rests upon the assumption that wages reflect the productivity of labour. This assumption is frequently made in economics, but is often violated - for example, in cases where labour is supplied by a monopoly supplier (trade union). In these cases wages can be maintained artificially above or below the wage rate which would prevail in a free market.

It should be noted that alternative methods exist by which lost productivity can be estimated. Actual resource costs will depend upon the ability of the employer to cover the productivity loss by the absent worker.

The costs of employee absenteeism will also depend upon other variables. Firstly, costs may exceed the estimates made by the human capital approach. Bensinger ${ }^{18}$ outlined problems such as the interruption of production schedules, requirement for overtime, the imposition of production quotas on fewer workers, and the impaired safety and questionable quality which result when employees are absent from work.

On the other hand, costs may be lower than the above estimates if employers can hire replacement labour or current employees can make up for the absence by working harder. Koopmanschap and colleagues ${ }^{19}$ presented the friction cost method which argued that the production loss should be confined to the period required for the employer to find replacement labour. This will in turn depend upon the rate of unemployment, the levels of state benefits, and the time required to train new employees. The human capital approach used above is therefore likely to fall between different theories outlined by Bensinger ${ }^{18}$ and Koopmanschap. ${ }^{19}$

A shortcoming of the results is that smoking related absence from work is likely to increase with age. Furthermore, since earnings profiles also tend to increase with age, the human capital approach may underestimate the true productivity cost. In addition, this analysis was unable to account for confounding effects as there are no data on individual smokers' characteristics such as social class.

PRODUCTIVITY LOSSES CAUSED BY EMPLOYEE SMOKING

Productivity losses are highly dependent upon the type of smoking policy which is operated by an employer. A policy permitting smokers to smoke in a designated area at any time is likely to result in the largest productivity losses, as smoke breaks can be taken in addition to the 
Table 4 Productivity loss caused by employee smoking

\begin{tabular}{|c|c|c|c|c|c|c|}
\hline & $\begin{array}{l}\text { Proportion of } \\
\text { sites }\end{array}$ & Employees & $\begin{array}{l}\text { Time lost } \\
\text { (minutes) }\end{array}$ & Wage & $\begin{array}{l}\text { Cost of } \\
\text { time/day }\end{array}$ & Total cost/day \\
\hline Smoke room & 0.533 & 162534 & 30 & $£ 11.22$ & $£ 5.61$ & $£ 938157$ \\
\hline Smoke free & 0.341 & 103985 & 10 & $£ 11.22$ & $£ 1.87$ & $£ 200070$ \\
\hline \multirow[t]{2}{*}{ No policy } & \multirow[t]{2}{*}{0.066} & \multirow[t]{2}{*}{$\begin{array}{l}20126 \\
286645\end{array}$} & 5 & $£ 11.22$ & $£ 0.94$ & $\begin{array}{l}\AA_{19362} \\
\AA_{1158588}\end{array}$ \\
\hline & & & \multicolumn{3}{|c|}{ Cost per annum (male) } & $£ 266254292$ \\
\hline Smoke & 0.533 & 152041 & 30 & $£ 9.05$ & $£ 4.53$ & $£ 646827$ \\
\hline Smoke free & 0.341 & 97272 & 10 & $£ 9.05$ & $£ 1.51$ & $£ 137941$ \\
\hline \multirow[t]{2}{*}{ No policy } & 0.066 & $\begin{array}{l}18827 \\
268141\end{array}$ & 5 & $£ 9.05$ & $\hat{£} 0.75$ & $\begin{array}{l}£ 13349 \\
£ 798117\end{array}$ \\
\hline & & & \multicolumn{3}{|c|}{ Cost per annum (female) } & $£ 183566980$ \\
\hline
\end{tabular}

breaks allowed to other workers. Productivity losses can be reduced by either requiring that workers "clock out" when they take smoke breaks, or restricting the times at which smoking is allowed to the breaks allowed to all workers. However, restrictions on times when smokers can smoke has been found to result in workers smoking in secret in certain areas of the premises, creating a fire risk as proper disposal facilities for matches and cigarette butts are not provided, and also leaving tobacco smoke in the air in toilets and other communal facilities.

The estimates of cigarette consumption are taken from Nelson's $s^{5}$ cost and benefit study of cigarette smoking in Northern Ireland, an area with a similar population and industrial structure to Scotland. Following Nelson, a moderate estimate of 5 cigarettes per day at an average of 6 minutes per cigarette represents a time loss of 30 minutes per day because of smoking. The author found these to be consistent with estimates from the USA. ${ }^{20}$ These times would appear to be relevant to worksites with a "smoke room" where employees are allowed to smoke at any time of the day, and smoking breaks are taken in addition to breaks taken by other workers. For worksites with no restrictions the time wasted uses an estimate of 5 minutes per day representing time spent lighting cigarettes, drawing on the cigarette, flicking the ash, and extinguishing the butt.

In order to calculate the productivity loss caused by smoking, the time spent on smoking is valued at the average wage rate. The estimated cost of the productivity loss to Scottish employers is shown in table 4. Part time workers are assumed to work for 15.2 hours per week. ${ }^{16}$

By summing the totals in table 4, the total productivity loss is therefore estimated at $£ 1955706$ per day, which is approximately $£ 450$ million per annum based on a 46 week year and 5 day week.

It is possible that productivity losses are also evident at smoke free worksites if employees are permitted to take smoke breaks in excess of usually permitted breaks, but have to leave the building.

A plausible assumption, given the absence of accurate data, may be that smokers can take unrestricted smoke breaks in $50 \%$ of smoke free buildings and $50 \%$ of buildings with smoke rooms, and that smoke breaks in these workplaces last for 30 minutes per day. The
Table 5 Cost of fire damage attributable to smoking: Scotland

\begin{tabular}{lll}
\hline $\begin{array}{l}\text { Source of ignition } \\
\text { Smokers materialst }\end{array}$ & $\begin{array}{l}\text { Proportion } \\
\text { attributable } \neq\end{array}$ & $\begin{array}{l}\text { Total cost of fire } \\
\text { damage (1993) }\end{array}$ \\
$\begin{array}{l}\text { Matches } \\
\text { Unknowns }\end{array}$ & 0.095 & $£ 40375000$ \\
$\quad$ Smokers' materials & 0.087 & $£ 36975000$ \\
Matches & 0.004 & $£ 1700000$ \\
& 0.004 & $£ 1700000$ \\
& & $£ 80750000$ \\
\hline
\end{tabular}

Adapted from Nelson. ${ }^{5}$

* Unknowns are allocated to smokers' materials and matches according to the proportion of other fires resulting from these sources.

†Smokers' materials, cigarettes, discarded cigarette butts, ash, cigars etc.

$\ddagger$ Attributable risks. ${ }^{5}$

cost of productivity loss with this assumption is an annual £288667871.

By varying the time spent taking smoke breaks, the total cost varies from an annual $£ 372$ million using zero productivity loss for smoke free buildings to $£ 605$ million where smokers spend 30 minutes taking smoke breaks under such restrictions.

However, it should be acknowledged that there may be positive effects on workplace performance associated with cigarette smoking. These could include improvements in worker concentration and reductions in stress levels. In addition, there may be negative morale effects of a smoking policy on smoking employees. ${ }^{21}$ Studies to date have omitted these potential benefits from their analysis.

FIRE DAMAGE TO BUSINESS PREMISES

Fire damage to business premises as a result of employee smoking is another cost to consider. Although firms are often insured against fire damage, ultimately businesses will share the cost through higher insurance premiums. The individual firm making the claim will bear a proportion of the cost if insurance premiums are experience rated (based on previous claims). Alternatively, the cost of covering the insurance claims may be spread across all employers, whether or not the employer a restrictive policy, through inflated premiums.

However, discounts for firms with no smoking policies were not available at five randomly sampled insurance companies, indicating that employee smoking is not considered to be a significant risk factor. This refuted the higher premiums that economic theory would predict. However, we include the cost of fire damage in these estimates as there is a resource cost if plant and equipment are destroyed.

The total insurance claims for fire damage to commercial premises in the UK for 1993 was $£ 425$ million. ${ }^{21}$ Allocated in proportion to the number of non-residential premises in Scotland this gives $£ 46854870$. Using the estimates of Nelson, ${ }^{5}$ the proportions attributable to smokers materials (cigarettes and ash) for the UK is $9.5 \%$, matches $8.7 \%$, and unknowns $4.6 \%$. These proportions may also be used to estimate the proportions of unknowns attributable to smokers' materials and matches. The estimated cost of fire damage attributable to smoking is shown in table 5 . The cost of fire damage to business 
premises in Scotland would therefore be $£ 4451213$ (inflated to 1998 prices). These costs of fire damage may be a conservative estimate. Costs will exceed the basic replacement cost for premises and equipment as the time lag between fire damage and the continuation of production will have associated disruption costs and a loss of output.

\section{OTHER COSTS}

Employee deaths and retirements caused by smoking related diseases also impose costs on employers. The cost will depend upon several factors such as how easily the labour can be replaced and the prevailing level of unemployment. In an economy with a high level of unemployment, costs will tend to be lower since there is a pool of replacement labour available. However, for specialist labour in short supply the costs to an employer may be significant. This would be the case, for example, if an employer employed labour which needed a lengthy training period. Hence the costs are very specific to each particular scenario.

In addition there are numerous other costs which must be taken into account such as clean up costs, redecoration costs, and potential damage to equipment such as computers and buildings, walls and floor coverings. In addition, research has pointed to a negative image presented by employees congregating outside a workplace to smoke, and the adverse effects on non-regular smokers in terms of perceived unfairness at extra breaks and take up of cigarette smoking by non-smokers. ${ }^{22}{ }^{23}$ These costs are specific to each particular employment situation and are extremely difficult to generalise.

\section{Conclusions}

The costs imposed on employers by employees who smoke are significant. The above estimates show that the annual cost of employee smoking in Scotland may be in the region of $£ 450$ million as a result of lost productivity, $£ 40$ million from higher rates of absenteeism among smokers, and $£ 4$ million as a result of fire damage. However, this estimate of the productivity loss is highly dependent on the assumptions made. Using a different set of assumptions, namely that $50 \%$ are smoke free buildings and $50 \%$ of premises with a smoke room allow unlimited smoke breaks, the estimated productivity loss is an annual $£ 288$ million. It should also be noted that the cost of absenteeism is highly dependent upon the estimate of excess absence from work by smokers. These cost estimates also exclude other possible costs such as cleaning, redecoration, and repairs to machinery. Furthermore, employers may face legal costs if they are found guilty of failing to protect non-smokers at work.

Estimating the costs which smokers impose on their employers is dependent upon many specific details of the actual employment scenario. The actual costs will depend upon many variables such as the type of labour employed and how easily labour is replaced, whether smoke breaks are permitted or not, how many cigarettes employees smoke (heavy versus light smokers), and the physical characteristics of the working environment. It is clear from this study that there is a limited research base from which to make precise estimates. It may also be more powerful in changing employers' attitudes if specific estimates could be modelled for individual companies. The figures presented here could be adapted to provide some estimates, but more accurate estimates would require a much larger body of country specific research.

However, from the estimates presented it is clear that employees who smoke do impose considerable costs on their employers. Cessation programmes to assist smokers to stop smoking do offer a significant potential for cost savings in the workplace, as well as health benefits for smokers.

The original research for this paper was financed by the Health Education Board for Scotland.

1 Repace JL, Lowrey AH. An enforceable indoor air quality standard for environmental tobacco smoke in the workplace. Risk Analysis 1993;13:463-75.

2 Action on Smoking and Health. Smoking at work: an employees guide to cleaning the air. London: ASH, 1994.

3 Van Tuinen M, Land G. Smoking and excess sick leave in a department of health. F Occup Med 1986;28:33-5.

4 Bertera RL. The effects of behavioural risks on absenteeism and health-care costs in the workplace. F Occup Med 1991; 33:1119-24.

5 Nelson H. The economic consequences of smoking in northern Ireland. Belfast: Ulster Cancer Foundation, 1986.

6 Hocking B, Borland R, Owen N, Kemp G. A total ban on workplace smoking is acceptable and effective. $f$ Occup Med 1991;33:163-7.

7 Kaiserman MJ. Costs of smoking in Canada. Chronic Diseases in Canada 1997;18:13-9.

8 Helyer AJ, Brehm WT. Economic consequences of tobacco use for the department of defense, 1995. Mil Med 1998;163:216-21.

9 Collins D, Lapsley H. The social costs of drug abuse in Australia in 1988 and 1992. Monograph Series No 30. Canberra, ACT: Australian Government publishing Service, 1996.

10 Hocking B, Grain H, Gordon I. Cost to industry of illnesses related to alcohol and smoking. Med $\mathcal{F}$ Aust 1994;161:40712

11 Barendregt JJ, Bonneux L, Van De Maas PJ. The health care costs of smoking. N Engl F Med 1997;337:1052-7. 12 Kompass UK. Register of British industry and commerce,

13 Godfrey C, Ensor T, Britton J, Maynard A, Robinson D. Alcohol costs and workplace policies: two surveys of employers. Addiction Research 1993;1:239-55.

14 Freeth S. Smoking related behaviour and attitudes, 1997. London: Office for National Statistics, 1998.

15 Anon. General household survey 1994. London: HMSO, 1996

16 Department of Employment. Labour market trends. London: HMSO, 1999.

17 Tsai SP, Gilstrap EL, Colangelo TA, Menard AK, Ross CE. Illness absence at an oil refinery and petrochemical plant. f Occup Environ Med 1997;39:455-62.

18 Bensinger PB. Drugs in the workplace: a commentary. Behavioural Sciences and the Law 1985;3:441-53.

19 Koopmanschap MA, Rutten FFH, van Ineveld M, van Roijen L. The friction cost method for measuring indirect costs of disease. F Health Econ 1995;14:171-89.

20 Warner KE, Wickizer TM, Wolfe RA, Schildroth JE, Samuelson $\mathrm{MH}$. Economic implications of workplace health promotion programmes: review of the literature. $f$ Occup Med 1988;30:106-12.

21 Association of British Insurers. Insurance Trends No. 8, January 1996, London: ABI, 1996.

22 Clarke J, Borland R, McGartland M. The effects of smoking outside workplaces on non-regular smokers. 7 Occup Environ Med 1997;39:734-9.

23 Gottlieb NH, Eriksen MP, Lovato CY, Weinstein RP, Green, LW. Impact of a restrictive worksite smoking policy on smoking behaviour, attitudes and norms. F Occup Med 1990;32:16-23. 